\title{
El predominio intelectual de los mulatos a fines de la dominación colonial hispana
}

\author{
The intellectual predominance of mulattoes \\ at the end of Hispanic colonial domination \\ DOI: https://doi.org/10.5377/koot.v0i11.10740 \\ URI: http://hdl.handle.net/11298/1196
}

Fernando Pérez Memén

Embajador de la República Dominicana en la República de El Salvador.

Dr. en Historia y Licenciado en Filosofía

emdosal@gmail.com

\section{Resumen}

Fecha de aceptación: diciembre 2020

A fin de garantizar su dominio en Santo Domingo, la corona española, estableció una política racial de valoración y reconocimiento legal del blanco y de subvaloración al indio, el negro, el árabe, el judío, el mestizo y los mulatos. En la segunda mitad del siglo XVIII, en las universidades de Santo Tomás de Aquino, de los dominicos, y la de Santiago de la Paz, de los jesuitas, en la iglesia, las milicias, en las oficinas reales y el comercio, iban penetrando los mulatos y ocupando posiciones de dirección a pesar de la política segregacionista de la corona, lo que preocupaba y atemorizaba a las autoridades españolas, como lo reveló el gobernador Azlor, en un informe secreto al rey sobre que de seguir esto los mulatos en poco tiempo tomarían el poder.

Palabras claves: Mulatos - Aspectos sociales - Historia - República Dominicana. República Dominicana - Historia - siglo XVIII - Vida social y costumbres. Mulatos - Vida social y costumbres - Historia - República Dominicana. Clases sociales $\neg$ - República Dominicana. Desigualdad social.

\begin{abstract}
The Spanish Crown, with the purpose of guaranteeing its power over Santo Domingo, established a racial policy to value and legally acknowledge whites and to undervalue indigenous people, blacks, Arabs, Jewish, mestizos, and
\end{abstract}




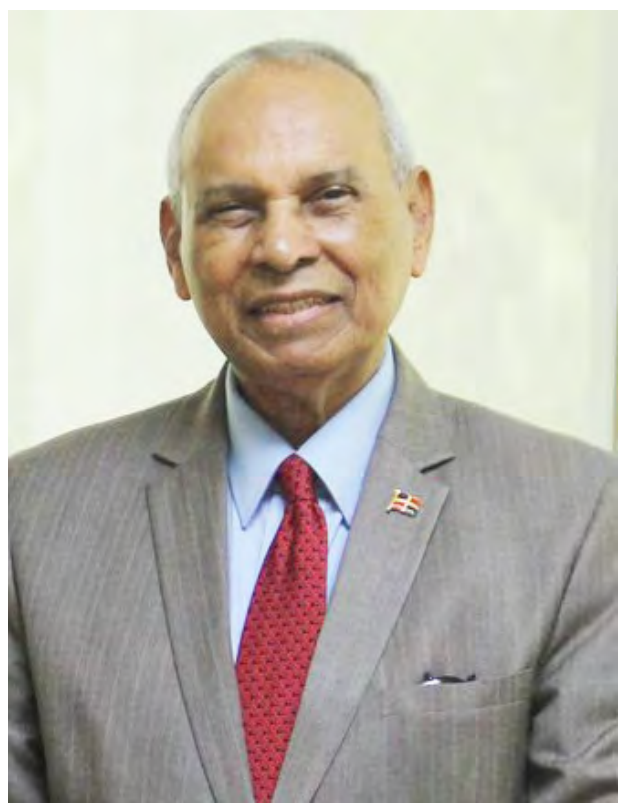

Fernando Pérez Memén

mulattoes. During the second half of the XVIII century, at church, the militia, the royal offices, commerce and at the universities of Santo Tomás - from the order of the dominicos - and Santiago de la Paz - from the Jesuit order--, mulattoes were penetrating and occupying leading positions in spite of the Crown's segregationist policy; this worried and frightened the Spanish authorities, as it was revealed by governor Azlor in a secret report to the King; if this situation continued, he wrote, they would take over power shortly.

Key words: Mulatos - Social aspects - History - Dominican Republic. Dominican Republic - History - 18th century - Social life and customs. Mulatos - Social life and customs - History - Dominican Republic. Social classes - Dominican Republic. Social inequality

La toma de la ciudad de Granada, último baluarte de Los Moros por Los Reyes Católicos, puso término a las guerras de reconquista. A partir de ese momento la política seguida por Fernando e Isabel fue lograr la integración del territorio peninsular sobre la base de la unidad racial y religiosa. Descubierto y conquistado el nuevo mundo, la corona inició el proceso de colonización aplicando esa política con la mayor radicalidad. 
Muchas reales cédulas prohibieron el ingreso a Las Indias de los judíos, árabes y otros extranjeros, cuya sangre fue considerada impura. Y en el caso de los indios, naturales del continente sometido, y los negros traídos del áfrica, la corona implantó una política segregacionista basada en argumentos ideológicos, que le permitió justificar y legitimar su dominio sobre ellos; a tenor de ella los consideró como razas inferiores, las cuales estaban determinadas por el derecho natural y el Derecho de Gentes a estar sujetas a las razas superiores, como las de los europeos.

El estamento dominante de las colonias, constituido por la aristocracia burocrática y latifundista frenó y desvió las luchas sociales hacia el plano religioso, fenómeno muy bien estudiado por Carlos Esteban Deive en su obra Heterodoxia e Inquisición en Santo Domingo (1492-1822), (Deive, 1983). Al tomar al judío como modelo de raza degenerada, lo que llevó a los plebeyos a preocuparse por rehabilitar su origen humilde exhibiendo la pureza de su raza; pero además del hebreo, raza impura era la del moro, el indio, el negro... en fin, aquellos cuyos orígenes raciales no estaban vinculados con el cristianismo.

Para impedir el ascenso de las clases dominadas a las estructuras del poder colonial, La Corona exigió la presentación de certificados de limpieza de sangre para ingresar a las universidades, a los seminarios, al estado eclesiástico, a la oficialidad militar, a los cargos burocráticos. La limpieza de sangre se entendía en su sentido genésico, es decir, a todo cuanto pudiese inyectar vida: simiente, leche. Juan de Pineda.

En la colonia de Santo Domingo, la política segregacionista de La Corona, pese a su radicalismo, no logró sus objetivos. El blanco no trajo a su mujer española, la temprana desaparición del indígena impidió el desarrollo del mestizaje, la importación de negros esclavos que asumieron la mano de obra en los ingenios, las plantaciones, las estancias y en los hatos llevó a que el ibero mezclara su sangre con el africano; así el blanco europeo se apareó, desde la segunda mitad del siglo xvi, con la negra, e inició el proceso de mulatización que alcanzó tan alto desarrollo, que en el siglo xviii los mulatos predominaban en número frente a los blancos y los negros, y traspasaban los límites de la política segregacionista del estado español, hasta formar parte del estamento dominante colonial.

El aumento de los mulatos, la acumulación de ciertos capitales de importancia y la capacidad intelectual que revelaban preocupó a muchos blancos en la América Hispana, Saint-Domingue (hoy Haití), y particularmente en Santo Domingo Español. El Arzobispo Domingo Fernández de Navarrete, en carta del 26/vii/ del 1683, informaba al Rey que los pardos solían decir "que dentro de pocos años vendría el gobierno a sus manos", y a pesar de la oposición de 
este prelado y de su sucesor, Fernando Carvajal y Rivera, a que los morenos recibieran órdenes sacerdotales, ellos alcanzaban el estado eclesiástico. Varios años antes de la prelacía de Carvajal y Rivera, el mitrado Francisco de la Cueva y Maldonado comunicaba al monarca, en 1675, que había en el clero algunas personas con "sangre de mulatos", y a fines de esa centuria el Padre Andrés de Solís, en unas letras en las que hacía una descripción de la isla y solicitaba un colegio para La Compañía de Jesús hablaba de un brillante "clérigo mulato que es un buen teólogo y predicador".

Mientras que en la América Española el prejuicio en contra de los mulatos aumentaba, en Santo Domingo Español, por el contrario, aminoraba. Muchos penetraban en las universidades de Santo Tomás de Aquino y en la de Santiago de la Paz, a pesar de que sus estatutos prohibían el ingreso de los que tuviesen en sus venas sangre africana, indígena, judía, árabe.En esas instituciones cursaban las carreras eclesiásticas y seculares, la falta de sacerdotes blancos para atender las necesidades religiosas de los fieles y el poco número de blancos instruidos y capaces para los empleos en la administración real, hizo que las autoridades eclesiásticas y civiles se rindiesen ante la realidad y fuesen abriendo las puertas de las dignidades y canonjías en la iglesia, y las magistraturas en el orden político.

El arzobispo, en 1706, pidió al Rey permiso para ordenar mulatos a condición de que no ocuparan prebendas, dignidades y canonjías, pero aquellos superaban los valladares que se le oponían y alcanzaban los referidos altos beneficios eclesiásticos. Uno de los más sobresalientes fue Pedro Morel de Santa Cruz, que a fines de 1715 ganó la oposición a la canonjía doctoral en virtud de sus "méritos personales". Se le admitió en esa dignidad a pesar de la protesta de algunos regidores del Ayuntamiento de la capital que le acusaban de ser hijo de una morena, y que sus padres habían vivido en amancebamiento. Más tarde logró ceñir en su frente la mitra episcopal y es el primer prelado dominicano. Fue obispo de Nicaragua (1751-1753), y luego de Santiago de Cuba (17531768), diócesis esta última que comprendía toda Cuba, Jamaica, La Florida y Luisiana. Escribió una historia de la isla y catedral de Cuba (Morell de Santa Cruz, 1929).

El más brillante intelectual dominicano del siglo xviii fue precisamente un mulato, Antonio Sánchez Valverde, a quien consideramos como el introductor del pensamiento moderno en Venezuela. Es el autor dominicano que revela una mayor influencia de las ideas del enciclopedismo, y su libro: Idea del Valor de la Isla la Española (Sánchez Valverde, 1785), es la mejor radiografía de nuestra realidad social en aquella centuria y el abogado más prominente que tuvo Santo Domingo en ese período fue un pardo, Juan Ignacio Rendón y Dorsuna, catedrático de derecho civil y de vísperas de cánones en la Universidad de Santo 
Tomás de Aquino, Fiscal del Arzobispado (1787-1789) y de la referida academia (1790-1794). Emigró en 1796 a Cuba donde alcanzó fama como jurista. El dato lo obtuvimos de un informe secreto del Gobernador de Santo Domingo, que encontramos en el Archivo General de Indias, en Sevilla. En ese documento la máxima autoridad colonial informaba a la corte el ascenso a dignidades y canonjías de mulatos que él consideraba talentosos.

Como se puede observar, en el ocaso de la dominación colonial hispana en Santo Domingo, la dirección intelectual iba cayendo en manos de los pardos que por sus talentos y virtudes superaban los prejuicios que la política segregacionista y exclusivista de La Corona había delineado para mantener sólo en manos blancas la dominación social, política y cultural de su primera colonia en el Nuevo Mundo.

\section{Referentes bibliográficos}

Deive, C. E. (1983). Heterodoxia e inquisición en Santo Domingo, 1942-1822. Santo Domingo, República Dominicana: Taller.

Morell de Santa Cruz, P. A. (1929). Historia de la isla y catedral de Cuba. Cuba: Cuba Intelectual.

Sánchez Valverde, A. (1785). Idea del valor de la Isla Española. Santo Domingo, República Dominicana: Montalvo. 
Pieza de Exposición

Museo Universitario de Antropología
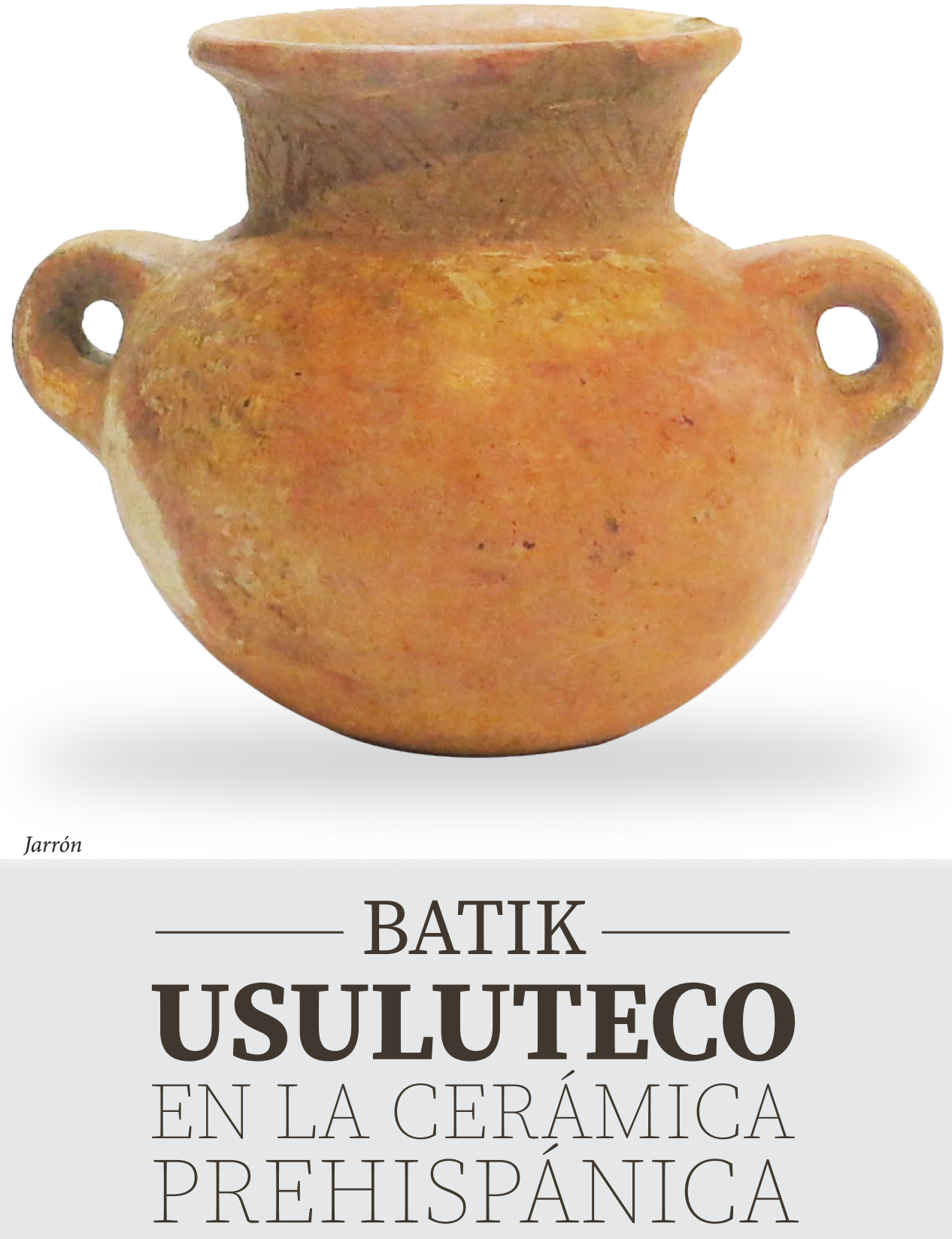